Article

\title{
Assessment of Excessive Acceleration of the IMO Second Generation Intact Stability Criteria for the Tanker
}

\author{
Dong-Min Shin ${ }^{1}(1)$ and Byung-Young Moon ${ }^{2, *}$ \\ 1 Institute for Security Convergence Research, Korea Advanced Institute of Science and Technology (KAIST), \\ 193 Munji-ro, Yuseong-gu, Daejeon 34051, Korea; ehdals9288@kaist.ac.kr \\ 2 Department of Shipbuilding and Ocean Engineering, Kunsan National University, 558 Daehak-ro, \\ Gunsan-si 54150, Korea \\ * Correspondence: moonby20@hanmail.net
}

check for

updates

Citation: Shin, D.-M.; Moon, B.-Y. Assessment of Excessive Acceleration of the IMO Second Generation Intact Stability Criteria for the Tanker. J. Mar. Sci. Eng. 2022, 10, 229. https:// doi.org/10.3390/jmse10020229

Received: 21 January 2022

Accepted: 3 February 2022

Published: 9 February 2022

Publisher's Note: MDPI stays neutral with regard to jurisdictional claims in published maps and institutional affiliations.

Copyright: (C) 2022 by the authors. Licensee MDPI, Basel, Switzerland. This article is an open access article distributed under the terms and conditions of the Creative Commons Attribution (CC BY) license (https:// creativecommons.org/licenses/by/ $4.0 /)$.

\begin{abstract}
Recently, the IMO (International Maritime Organization) has reviewed technical issues considering the second generation intact stability criteria in the design stage of ships. In this paper, the evaluation procedure for Lv1 (Level 1) and Lv2 (Level 2) was introduced by focusing on the excessive acceleration mode. Based on real ship data, the calculation process has been explained in detail to make it easy to understand. When the Lv1 criteria considering simple hydrostatic calculations are not satisfied, the computational results of the Lv2 criteria based on mathematical modeling and the hydrodynamics are presented. The relatively low ship roll periods and large changes in the hull shape in the vertical direction make the ships potentially vulnerable to excessive acceleration phenomena. Therefore, the minimum value of height KG that satisfies the stability criteria evaluation in consideration of loading conditions for actually navigating of the ship in the sea should be estimated and operated. In particular, roll damping coefficients using the Ikeda's method, which are essential for Lv2 vulnerability calculation, were obtained and verified by comparing them with other ship results.
\end{abstract}

Keywords: IMO second generation intact stability criteria; excessive acceleration; roll period; roll damping coefficient

\section{Introduction}

The IMO (International Maritime Organization) has recently developed the second generation intact stability criteria for the five stability failure modes (pure loss of stability, parametric roll, surf-riding/broaching, dead ship condition, and excessive acceleration) to secure the safe navigation of ships [1,2]. The second generation intact stability criteria consist of two steps. The first step (Lv1) is an assessment based on a simple physical-based vulnerability criterion using the ship design data. Meanwhile, the second step (Lv2) is a process of applying a mathematical modelling and evaluating it based on the probabilistic calculations in wave conditions. The five vulnerable modes of the intact stability criteria are briefly described as follows.

(1) The pure loss of stability drastically reduces the stability of the vessel when the midpoint of the hull and the wave crest are same.

(2) The parametric roll is a resonance that happens if the incident wave frequency on the ship is twice of the resonance roll frequency.

(3) When a ship's engine breaks down, the phenomenon that occurs due to the roll occurring when waves enter from the side of the hull is called the dead ship condition.

(4) The surf-riding is formed when a vessel goes in the following wave, and the ship's stability becomes weak as the vessel ride waves in a situation where the wave speed and the ship speed are nearly the same. In the broaching, the ship loses directional stability while the surf-riding continues, resulting in a loss of stability in a maneuverable state $[3,4]$. 
(5) The phenomenon of cargo falling overboard due to acceleration caused by the restoring force caused by GM, metacentric height is called excessive acceleration.

In this study, calculation procedures and results are presented for the excessive acceleration mode among five causes of loss of stability. Prior to this, the process of occurrence of excessive acceleration mode is described in detail in Figure 1 as follows [5].

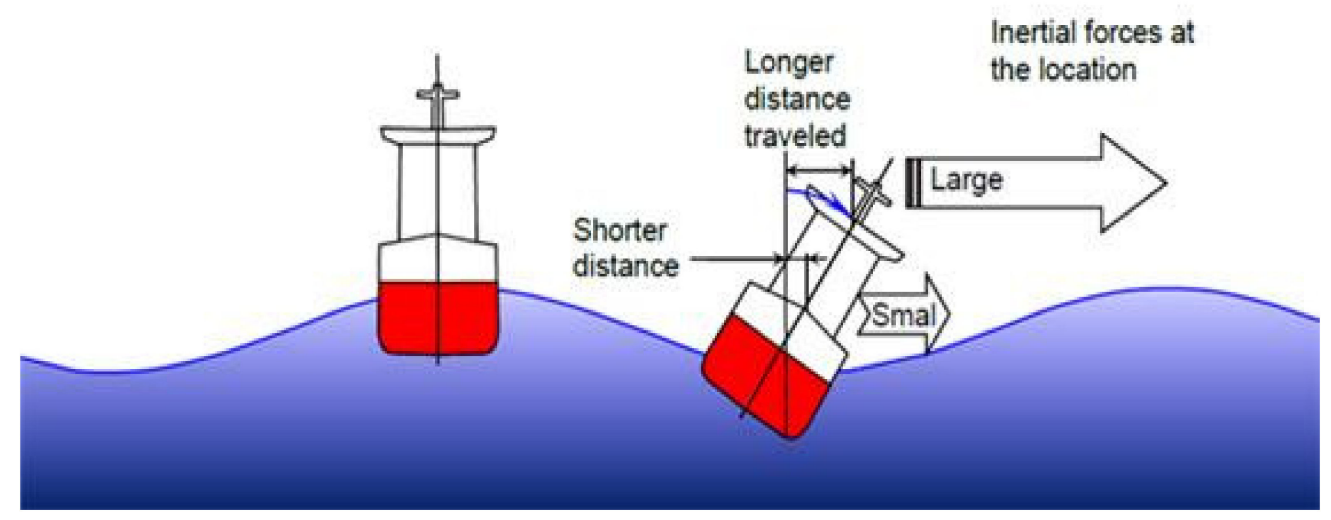

Figure 1. Scenario of stability failure related to excessive acceleration mode [5].

(a) When a ship is rolling, the objects in higher locations travel longer distances. A period of roll motions is the same for all the location onboard the ship [5].

(b) To cover longer distance during the same time, the linear velocity must be larger. As the velocity changes its direction every half a period, larger linear velocity leads to larger linear accelerations. Large linear acceleration means lager inertial force [5].

(c) Large accelerations are mostly caused by roll motions so they have predominantly lateral direction [5].

(d) If the GM value is large, the period of roll motion is smaller. Thus, for the same roll amplitude the changes of linear velocity occur faster, so accelerations are larger [5].

The research on the stability criteria of excessive acceleration mode Lv1 and Lv2 was revised depending on several criteria the IMO draft.

(a) [6,7]: Modified draft IS (International Standard) Code for Lv1 and Lv2 Vulnerability criteria for excessively acceleration

(b) [8,9]: Explanatory notes about the vessel's vulnerability to excessive acceleration

(c) [10]: Description of excessive acceleration Lv2 criteria

The Lv1 criterion is based on a dimensionless expression related to the conditions of the ship's loading and weather. In the probabilistic distribution condition of the wave spectrum, the Lv2 criterion is calculated by the summation of the weight function. Unlike Lv1, in Lv2, the calculation of the stability of the ship is performed in waves. Therefore, in this paper, focusing on the most recent update draft, [11,12], stipulated by the IMO SDC Sub-committee, when the Lv1 is not satisfied, mathematical modeling and calculation method for performing complex calculations based on the Lv2 including dynamic stability in waves is presented, and calculations are performed by applying them to an actual ship (13 K oil chemical tanker) through the developed code.

\section{Theory}

\subsection{Lv1 Vulnerability Criterion}

The Lv1 criterion for each loading and position conditions along the longitudinal direction of the ship where passengers or sailor and cargo may be present, is considered to be that the vessel is not vulnerable to excessive acceleration under following conditions such as Equation (1) [12].

$$
\phi \cdot k_{L} \cdot\left(g+\frac{4 \pi^{2} h_{r}}{T_{r}^{2}}\right) \leq R_{E A 1}
$$


where

$R_{E A 1}=4.64 \mathrm{~m} / \mathrm{s}^{2}$

g: gravitational acceleration $\left(=9.81 \mathrm{~m} / \mathrm{s}^{2}\right)$

$k_{L}=\left\{\begin{array}{c}1.125-0.625 x / L \text { if } x<0.2 L \\ 1.0 \text { if } 0.2 L \leq x \leq 0.65 L \\ 0.527+0.727 x / L \text { if } x>0.65 L\end{array}\right.$

$k_{L}$ is coefficient that reflect the action of roll, yaw, and pitch motions. $x$ is longitudinal distance of the position where sailor or passengers can be located from the aft end of $L$ (ship length). $h_{r}$ is height above the estimated roll axis of the position where sailor or passengers can be located. We can assume the roll axis to be located midway between the waterline and the vertical center of gravity.

$$
\phi=4.43 r s / \delta_{\phi}^{0.5}: \text { Characteristic roll amplitude }
$$

$\delta_{\phi}$ : Nondimensionalized logarithmic decrement of roll decay

$r$ in Equation (2) is the effective wave slope coefficient.

$$
r=\frac{K_{1}+K_{2}+(O G)(F)}{\frac{B^{2}}{12 C_{B} d}-\frac{C_{B} d}{2}-O G}
$$

where

$O G=K G-d$

$K G$ can be considered as the height of the center of gravity above the baseline corresponding to the load condition. $d$ is mean draft and $B$ is breadth of the vessel.

$$
\begin{aligned}
& K_{1}=g \beta T_{r}^{2}(\tau+\tau \widetilde{T}-1 / \widetilde{T}) /\left(4 \pi^{2}\right) \\
& K_{2}=g \tau T_{r}^{2}(\beta-\cos \widetilde{B}) /\left(4 \pi^{2}\right) \\
& \beta=\sin (\widetilde{B}) / \widetilde{B} \\
& \tau=\exp (-\widetilde{T}) / \widetilde{T} \\
& \widetilde{B}=2 \pi^{2} B /\left(g T_{r}^{2}\right) \\
& \widetilde{T}=4 \pi^{2} C_{B} d /\left(g T_{r}^{2}\right) \\
& F=\beta(\tau-1 / \widetilde{T}) \\
& T_{r}: \text { Natural roll period }
\end{aligned}
$$

$s$ in Equation (2) is a wave steepness function of the natural roll frequency $T_{r}$ in Table 1. The value of $s$ is estimated by interpolation according to the range of the natural roll frequency. The intermediate value in Table 1 should be obtained through linear interpolation. The function for $s$ obtained in Figure 2 is as in Equation (3), and the coefficient values $\left(w_{0}-w_{6}\right)$ are shown in Table 2 .

$$
s\left(T_{r}\right)=w_{0}+w_{1} T_{r}+w_{2} T_{r}^{2}+w_{3} T_{r}^{3}+w_{4} T_{r}^{4}+w_{5} T_{r}^{5}+w_{6} T_{r}^{6}
$$

\subsection{Lv2 Vulnerability Criterion}

For Lv2 criterion, the vessel can be judged to be stable from excessive acceleration mode under the following Equation (4) conditions [12].

$$
C=\sum_{i=1}^{N} W_{i} C_{S, i} \leq R_{E A 2}
$$

where

$$
\begin{aligned}
& R_{E A 2}=0.00039 \\
& C_{S, i}=\exp \left(-R_{2}{ }^{2} /\left(2 \sigma_{L A i}{ }^{2}\right)\right) \\
& R_{2}=9.81 \mathrm{~m} / \mathrm{s}^{2}
\end{aligned}
$$


Table 1. Value of wave steepness, $s(=H / \lambda: H$ is wave height and $\lambda$ is wavelength) [12].

\begin{tabular}{cc}
\hline Natural Roll Period $T_{\boldsymbol{r}}(\boldsymbol{s})$ & Wave Steepness $s=H / \lambda$ \\
\hline$<6$ & 0.1 \\
6 & 0.1 \\
7 & 0.098 \\
8 & 0.093 \\
12 & 0.065 \\
14 & 0.053 \\
16 & 0.044 \\
18 & 0.038 \\
20 & 0.032 \\
22 & 0.028 \\
24 & 0.025 \\
26 & 0.023 \\
28 & 0.021 \\
30 & 0.02 \\
$>30$ & 0.02 \\
\hline
\end{tabular}

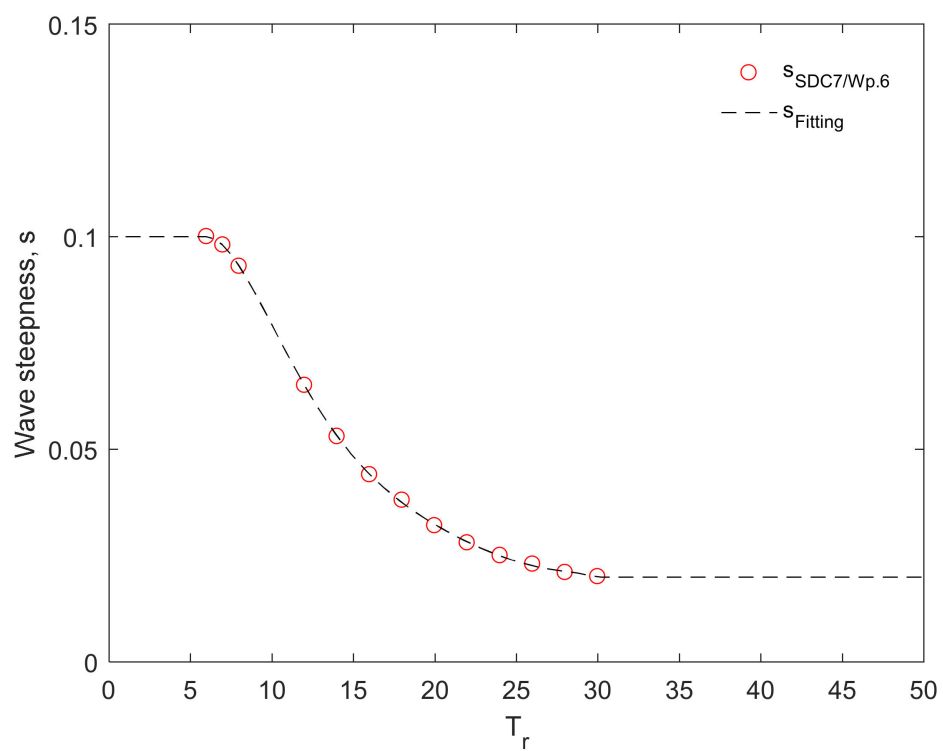

Figure 2. Wave steepness, s obtained through linear interpolation in Table 1.

Table 2. Values of the coefficients in Equation (3), w.

\begin{tabular}{ccccccc}
\hline$w_{0}$ & $w_{1}$ & $w_{2}$ & $w_{3}$ & $w_{4}$ & $w_{5}$ & $w_{6}$ \\
\hline-0.07668 & 0.081022 & -0.01338 & 0.001011 & $-4.03 \times 10^{-5}$ & $8.25 \times 10^{-7}$ & $-6.82 \times 10^{-9}$ \\
\hline
\end{tabular}

The $\sigma_{L A i}$ is standard deviation of the lateral acceleration at velocity 0 and in a beam seaway determined, shown in Equation (5).

$$
\sigma_{L A i}^{2}=\frac{3}{4} \sum_{i=1}^{N}\left(a_{y}\left(\omega_{j}\right)\right)^{2} S_{z z}\left(\omega_{j}\right) \Delta \omega
$$

where

$\Delta \omega:$ Interval of wave frequency $(\mathrm{rad} / \mathrm{s})=\left(\omega_{2}-\omega_{1}\right) / N(\mathrm{rad} / \mathrm{s})$

$\omega_{2}$ : Upper frequency limit of the wave spectrum in the evaluation range $=\min \left(\left(25 / T_{r}\right)\right.$, 2.0) $(\mathrm{rad} / \mathrm{s})$

$\omega_{1}$ : Lower frequency limit of the wave spectrum in the evaluation range $=\max \left(\left(0.5 / T_{r}\right)\right.$, $0.2)(\mathrm{rad} / \mathrm{s})$ 
$N$ : Number of intervals of wave frequency in the evaluation range, not to be taken less than 100

$\omega_{j}$ : Wave frequency at the mid-point of the considered frequency

Interval: $\omega_{1}+((2 j-1) / 2) \Delta \omega(\mathrm{rad} / \mathrm{s})$

$S_{z z}\left(\omega_{j}\right)$ : Sea wave elevation spectrum $\left(\mathrm{m}^{2} /(\mathrm{rad} / \mathrm{s})\right)$.

$a_{y}\left(\omega_{j}\right)$ : Lateral acceleration $=$ per unit wave amplitude $\left(\left(\mathrm{m} / \mathrm{s}^{2}\right) / \mathrm{m}\right)$

$a_{y}\left(\omega_{j}\right)$ in Equation (5) is expressed in Equation (6).

$$
a_{y}\left(\omega_{j}\right)=k_{L}\left(g+h_{r} \cdot \omega_{j}^{2}\right) \cdot \phi_{a}\left(\omega_{j}\right)
$$

where, $\varphi_{a}\left(\omega_{j}\right)$ in Equation (6) is roll amplitude of a regular beam wave with unit amplitude and frequency $\omega_{j}$ at velocity $0(\mathrm{rad} / \mathrm{s}) . \varphi_{a}$ consists of the square root of the sum of the squares of $\varphi_{r}$ and $\varphi_{i}$ in Equation (7).

$$
\phi_{a}\left(\omega_{j}\right)=\sqrt{\phi_{r}\left(\omega_{j}\right)^{2}+\phi_{i}\left(\omega_{j}\right)^{2}}
$$

where

$$
\begin{aligned}
& \phi_{r}\left(\omega_{j}\right)=\frac{a\left(\frac{\rho g \nabla G M}{1000}-J_{T, \text { roll }} \omega_{j}^{2}\right)+b B_{e} \omega_{j}}{\left(\frac{\rho g \nabla G M}{1000}-J_{T, \text { roll }} \omega_{j}^{2}\right)+\left(B_{e} \omega_{j}\right)^{2}} \\
& \phi_{i}\left(\omega_{j}\right)=\frac{b\left(\frac{\rho g \nabla G M}{1000}-J_{T, \text { roll }} \omega_{j}^{2}\right)-a B_{e} \omega_{j}}{\left(\frac{\rho g \nabla G M}{1000}-J_{T, \text { roll }} \omega_{j}^{2}\right)+\left(B_{e} \omega_{j}\right)^{2}}
\end{aligned}
$$

$a$ in Equation (8) is a cosine component and $b$ in Equation (9) is a sine component of the Froude-Krylov roll moment in regular beam waves of unit amplitude $(\mathrm{kN} \cdot \mathrm{m} / \mathrm{m})$. The equation of the Froude-Krylov roll moment [13] is equal to Equation (10).

$$
\sum \vec{M}=\int_{A} \rho\left(\varphi_{I}+\varphi_{D}\right) n_{j} \times \vec{r} d s
$$

where, $\rho$ is water density, $\varphi_{I}$ and $\varphi_{D}$ are the incident and diffraction wave potentials. $J_{T, \text { roll }}$, $B_{e}, \mu_{e}$ in Equations (8) and (9) are as follows. Equivalent linear roll damping $B_{e}$ is discussed in detail in the next chapter.

$$
\begin{gathered}
J_{T, \text { roll }}=\frac{1}{1000} \frac{\rho g \nabla G M T_{r}^{2}}{4 \pi^{2}} \\
B_{e}=2 J_{T, \text { roll }} \mu_{e}
\end{gathered}
$$

where,

$J_{T, \text { roll }}$ : Roll moment of inertia comprising added inertia $\left(\mathrm{t} \cdot \mathrm{m}^{2}\right)$

$B_{e}$ : Equivalent linear roll damping factor $(\mathrm{kN} \cdot \mathrm{m} \cdot \mathrm{s})$

$\mu_{e}$ : Equivalent linear roll damping coefficient $(1 / s)$

The standard expression for $S_{z z}(\omega)$ in Equation (5) is as follows. $S_{z z}$ is the sea elevation spectrum and is composed of the zero-crossing wave period $T_{z}$ and the significant wave height $H_{S}$.

$$
S_{z z}(\omega)=\frac{H_{s}^{2}}{4 \pi}\left(\frac{2 \pi}{T_{z}}\right)^{2} \omega^{-5} \exp \left(-\frac{1}{\pi}\left(\frac{2 \pi}{T_{z}}\right)^{4} \omega^{-4}\right)
$$

In the calculation of the $C$ value for Lv2 vulnerability criterion verification in Equation (4), where, $W_{i}$ is weighting factor the short-term environmental condition and $N$ is total number of short-term environmental condition using the data in Table 3 [12]. $W_{i}$ is obtained from the data in Table 2 divided by 100,000, which is the value of observation number. 
Table 3. Wave case occurrences [12].

\begin{tabular}{|c|c|c|c|c|c|c|c|c|c|c|c|c|c|c|c|c|}
\hline \multicolumn{17}{|c|}{ Number of Occurrences: $100,000 / T_{z}(s)=$ Average Zero Up-Crossing Wave Period } \\
\hline $\begin{array}{l}T_{z} \rightarrow \\
H_{s} \downarrow\end{array}$ & 3.5 & 4.5 & 5.5 & 6.5 & 7.5 & 8.5 & 9.5 & 10.5 & 11.5 & 12.5 & 13.5 & 14.5 & 15.5 & 16.5 & 17.5 & 18.5 \\
\hline 0.5 & 1.3 & 133.7 & 865.6 & 1186 & 634.2 & 186.3 & 36.9 & 5.6 & 0.7 & 0.1 & 0 & 0 & 0 & 0 & 0 & 0 \\
\hline 1.5 & 0 & 29.3 & 986 & 4976 & 7738 & 5569.7 & 2375.7 & 703.5 & 160.7 & 30.5 & 5.1 & 0.8 & 0.1 & 0 & 0 & 0 \\
\hline 2.5 & 0 & 2.2 & 197.5 & 2158.8 & 6230 & 7449.5 & 4860.4 & 2066 & 644.5 & 160.2 & 33.7 & 6.3 & 1.1 & 0.2 & 0 & 0 \\
\hline 3.5 & 0 & 0.2 & 34.9 & 695.5 & 3226.5 & 5675 & 5099.1 & 2838 & 1114.1 & 337.7 & 84.3 & 18.2 & 3.5 & 0.6 & 0.1 & 0 \\
\hline 4.5 & 0 & 0 & 6 & 196.1 & 1354.3 & 3288.5 & 3857.5 & 2685.5 & 1275.2 & 455.1 & 130.9 & 31.9 & 6.9 & 1.3 & 0.2 & 0 \\
\hline 5.5 & 0 & 0 & 1 & 51 & 498.4 & 1602.9 & 2372.7 & 2008.3 & 1126 & 463.6 & 150.9 & 41 & 9.7 & 2.1 & 0.4 & 0.1 \\
\hline 6.5 & 0 & 0 & 0.2 & 12.6 & 167 & 690.3 & 1257.9 & 1268.6 & 825.9 & 386.8 & 140.8 & 42.2 & 10.9 & 2.5 & 0.5 & 0.1 \\
\hline 7.5 & 0 & 0 & 0 & 3 & 52.1 & 270.1 & 594.4 & 703.2 & 524.9 & 276.7 & 111.7 & 36.7 & 10.2 & 2.5 & 0.6 & 0.1 \\
\hline 8.5 & 0 & 0 & 0 & 0.7 & 15.4 & 97.9 & 255.9 & 350.6 & 296.9 & 174.6 & 77.6 & 27.7 & 8.4 & 2.2 & 0.5 & 0.1 \\
\hline 9.5 & 0 & 0 & 0 & 0.2 & 4.3 & 33.2 & 101.9 & 159.9 & 152.2 & 99.2 & 48.3 & 18.7 & 6.1 & 1.7 & 0.4 & 0.1 \\
\hline 10.5 & 0 & 0 & 0 & 0 & 1.2 & 10.7 & 37.9 & 67.5 & 71.7 & 51.5 & 27.3 & 11.4 & 4 & 1.2 & 0.3 & 0.1 \\
\hline 11.5 & 0 & 0 & 0 & 0 & 0.3 & 3.3 & 13.3 & 26.6 & 31.4 & 24.7 & 14.2 & 6.4 & 2.4 & 0.7 & 0.2 & 0.1 \\
\hline 12.5 & 0 & 0 & 0 & 0 & 0.1 & 1 & 4.4 & 9.9 & 12.8 & 11 & 6.8 & 3.3 & 1.3 & 0.4 & 0.1 & 0 \\
\hline 13.5 & 0 & 0 & 0 & 0 & 0 & 0.3 & 1.4 & 3.5 & 5 & 4.6 & 3.1 & 1.6 & 0.7 & 0.2 & 0.1 & 0 \\
\hline 14.5 & 0 & 0 & 0 & 0 & 0 & 0.1 & 0.4 & 1.2 & 1.8 & 1.8 & 1.3 & 0.7 & 0.3 & 0.1 & 0 & 0 \\
\hline 15.5 & 0 & 0 & 0 & 0 & 0 & 0 & 0.1 & 0.4 & 0.6 & 0.7 & 0.5 & 0.3 & 0.1 & 0.1 & 0 & 0 \\
\hline 16.5 & 0 & 0 & 0 & 0 & 0 & 0 & 0 & 0.1 & 0.2 & 0.2 & 0.2 & 0.1 & 0.1 & 0 & 0 & 0 \\
\hline
\end{tabular}

\section{Lv1 Vulnerability Criterion Assessment of Excessive Acceleration Mode}

In this chapter, for the evaluation of Lv1 and Lv2 of the excessive acceleration vulnerability criteria evaluation, the calculations were performed by referring to the data of $13 \mathrm{~K}$ oil chemical tanker [13] in Table 4. The sectional area in Table 5 depending on the position of the longitudinal section of the $13 \mathrm{~K}$ oil chemical tanker is shown in Figure 3. It can be seen that the bottom of the tanker is relatively flat.

Table 4. Main dimensions of $13 \mathrm{~K}$ oil chemical tanker [14].

\begin{tabular}{cc}
\hline Parameters & 13 K Oil Chemical Oanker \\
\hline Length $L(\mathrm{~m})$ & 120.4 \\
Breadth $B(\mathrm{~m})$ & 20.4 \\
Draft $d(\mathrm{~m})$ & 8.7 \\
Block coefficient $C_{B}$ & 0.8 \\
Midship coefficient $C_{M}$ & 0.995 \\
Prismatic coefficient $C_{p}\left(=C_{B} / C_{M}\right)$ & 0.8 \\
Displacement $\Delta($ ton $)$ & $17,457.3$ \\
Midship section area $\left(\mathrm{m}^{2}\right)$ & 176.5 \\
Length of waterline $(\mathrm{m})$ & 123.76 \\
Bilge keel area $\left(\mathrm{m}^{2}\right)$ & 33.1 \\
$G M(\mathrm{~m})$ & 1.472 \\
$K G(\mathrm{~m})$ & 7.304 \\
\hline
\end{tabular}

Table 5. The sectional area according to the location of the longitudinal section of the $13 \mathrm{~K}$ oil chemical tanker [14].

\begin{tabular}{|c|c|c|c|c|c|c|c|c|c|}
\hline $\begin{array}{l}\text { Location } \\
\text { (m) }\end{array}$ & $\begin{array}{l}\text { Area } \\
\left(\mathrm{m}^{2}\right)\end{array}$ & $\begin{array}{c}\text { Location } \\
\text { (m) }\end{array}$ & $\begin{array}{l}\text { Area } \\
\left(\mathrm{m}^{2}\right)\end{array}$ & $\begin{array}{l}\text { Location } \\
\text { (m) }\end{array}$ & $\begin{array}{l}\text { Area } \\
\left(\mathrm{m}^{2}\right)\end{array}$ & $\begin{array}{c}\text { Location } \\
\text { (m) }\end{array}$ & $\begin{array}{l}\text { Area } \\
\left(\mathrm{m}^{2}\right)\end{array}$ & $\begin{array}{l}\text { Location } \\
\text { (m) }\end{array}$ & $\begin{array}{l}\text { Area } \\
\left(\mathrm{m}^{2}\right)\end{array}$ \\
\hline-3.000 & 2.9 & 21.070 & 142.2 & 48.160 & 176.5 & 75.250 & 176.5 & 102.340 & 137.5 \\
\hline-1.500 & 8.8 & 24.080 & 153.8 & 51.170 & 176.5 & 78.260 & 176.4 & 105.350 & 122.2 \\
\hline 0.000 & 12.6 & 27.090 & 162.2 & 54.180 & 176.5 & 81.270 & 176.0 & 108.360 & 104.4 \\
\hline 0.3010 & 22.1 & 30.100 & 168.0 & 57.190 & 176.5 & 84.280 & 175.2 & 111.370 & 84.2 \\
\hline 6.020 & 44.2 & 33.110 & 171.7 & 60.200 & 176.5 & 87.290 & 173.6 & 114.380 & 62.5 \\
\hline 9.030 & 67.1 & 36.120 & 174.0 & 63.210 & 176.5 & 90.300 & 170.8 & 117.390 & 40.5 \\
\hline 12.040 & 89.0 & 39.130 & 175.3 & 66.220 & 176.5 & 93.310 & 166.2 & 120.400 & 17.8 \\
\hline 15.050 & 109.3 & 42.140 & 176.0 & 69.230 & 176.5 & 96.320 & 159.4 & 122.150 & 8.7 \\
\hline 18.060 & 127.3 & 45.150 & 176.4 & 72.240 & 176.5 & 99.330 & 149.9 & & \\
\hline
\end{tabular}




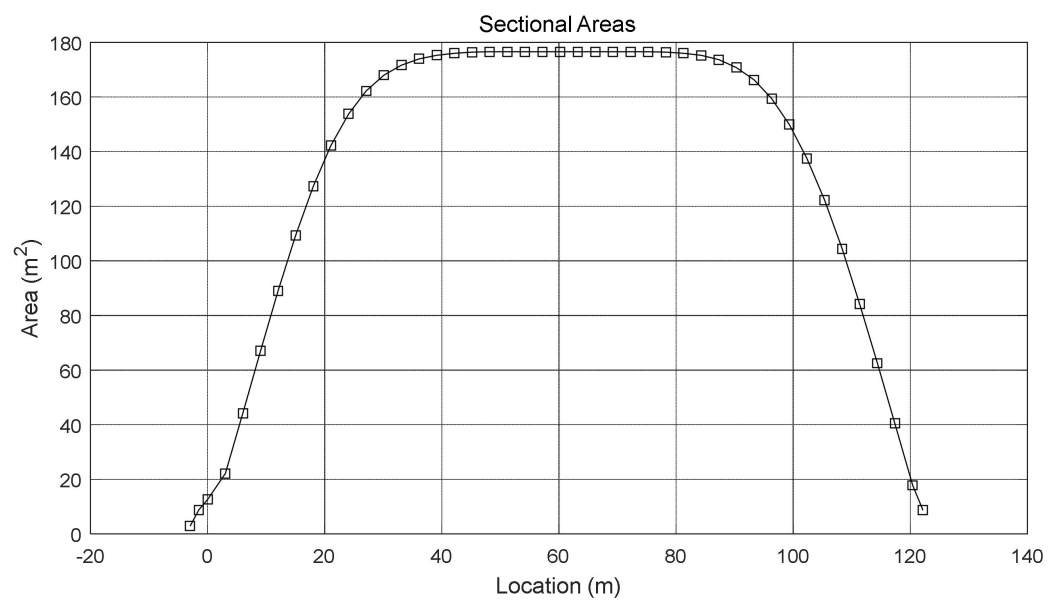

Figure 3. Sectional area depending on the longitudinal section location of the tanker.

If $x / L=0.65$, which is ratio of longitudinal distance $x$ of the location where sailor or passenger can be located from the aft end of the ship and the ship length, Figure 4 shows the Lv1 vulnerability criterion calculation results of excessive acceleration mode. According to the $h_{r}$, which is height above the estimated roll axis of the location where sailor or passenger can be located, the assessment on the excessive acceleration vulnerability criterion Lv1. In Figure $4 \mathrm{a}$, if the $h_{r}$ is approximately 50 less, the section that can maintain the stability of the vessel by passing the excessive acceleration Lv1 criterion (Satisfied, $\leq R_{E A 1}\left(=4.64 \mathrm{~m} / \mathrm{s}^{2}\right)$ ), and the section (Unsatisfied, $>R_{E A 1}\left(=4.64 \mathrm{~m} / \mathrm{s}^{2}\right)$ ) that exceeds the $h_{r} \approx 50$ is the section that does not pass the Lv1 standard, the calculation for the Lv2 criterion need to be carried out. In Figure $4 \mathrm{~b}, h_{r}$ is fixed and expressed in Equation (14).

$$
h_{r}=H-(K G+d) / 2
$$

where, $H$ is the height of the navigational deck above keel. In Figure $4 \mathbf{b}$, when $h_{r}$ is 16.998 (m), the Lv1 criterion is satisfied in all sections of longitudinal distance $\mathrm{x}$, but as $h_{r}$ increases, it is found that it is particularly vulnerable to the front and rear parts of the hull. This means that the higher the height of the center of gravity of the roll axis of the hull by the crew or cargo, the weaker the front and rear parts of the hull. According to the procedure for calculating the Lv2 criterion, the value of $C$, which is the criterion for evaluating the stability of the Lv2, should be calculated.

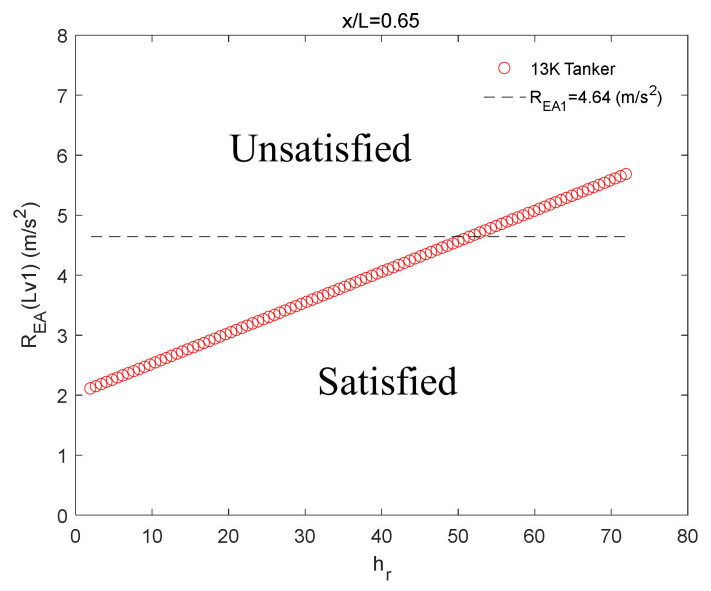

(a)

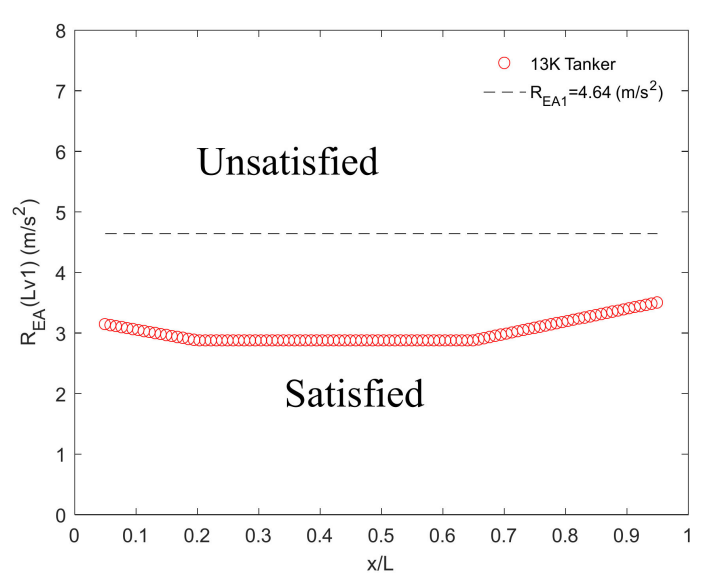

(b)

Figure 4. Lv1 vulnerability criterion assessment for excessive acceleration mode of the $13 \mathrm{~K}$ oil chemical tanker. (a) $x / L=0.65$, (b) $h_{r}=16.998(\mathrm{~m})$. 


\section{Lv2 Vulnerability Criterion Assessment of Excessive Acceleration Mode}

Equivalent linear roll damping $B_{e}$ is the most important coefficient in the excessive acceleration mode Lv2 judgment and is calculated by the Ikeda's method. In this paper, it is expressed as follows with reference to [15].

$$
\begin{gathered}
\hat{B}_{44}=\frac{B_{44}}{\rho \nabla B^{2}} \sqrt{\frac{B}{2 g}} \\
B_{44}=B_{F}+B_{E}+B_{L}+B_{B K}+B_{W}
\end{gathered}
$$

where,

$B_{F}$ : Frictional component

$B_{E}$ : Eddy component

$B_{L}$ : Lift component

$B_{B K}$ : Bilge keel component

$B_{W}$ : Wave component

First, the $Q 1-Q 7$ values to be used in the calculation of each component are shown in the [5].

The linear roll damping $B_{e}$ is composed of the sum of five damping components. First damping component is the frictional damping coefficient $B_{F}$ in Equation (17).

$$
B_{F}=\frac{4}{3 \pi} \rho s_{f} r_{f}^{3} \varphi_{a} \omega c_{f}
$$

where

$c_{f}$ : Frictional coefficient

$r_{f}:$ Average radius from the axis of rolling

$s_{f}$ : Wetted surface area

The coefficients $c_{f}$, sf and $r_{f}$ in Equation (17) are as shown in Equations (18)-(20).

$$
\begin{gathered}
c_{f}=0.75 \frac{\sqrt{T_{\varphi} v}}{r_{f} \varphi_{a}} \\
s_{f}=L\left(1.75 d+C_{b} B\right) \\
r_{f}=\frac{\left(0.887+0.145 C_{b}\right) \cdot\left(1.7 d+C_{b} B\right)-2 O G}{\pi}
\end{gathered}
$$

where

$\varphi_{a}:$ Roll amplitude

$T_{\varphi}:$ Roll period

$v$ : The coefficient of dynamic viscosity

$O G=K G-d$

Second damping component is the eddy damping coefficient $B_{E}$ in Equation (21).

$$
\hat{B}_{E}=\frac{4 \hat{\omega} \varphi_{a}}{3 \pi x_{2} x_{1}{ }^{3}} C_{R}
$$

The coefficients in Equation (21) are as shown in Equations (22)-(26).

$$
\begin{gathered}
C_{R}=A_{E} \exp \left(B_{E 1}+B_{E 2} x_{3}{ }^{B_{E 3}}\right) \\
A_{E}=\left(-0.0182 x_{2}+0.0155\right) \cdot\left(x_{1}-1.8\right)^{3}+\sum_{i=1}^{5} Q 6_{1, i} x_{2}{ }^{5-i}
\end{gathered}
$$




$$
\begin{gathered}
B_{E 1}=\left(-2 x_{1}+1.6\right) \cdot\left(3.98 x_{2}-5.1525\right) \cdot \frac{O G}{d} \cdot\left(\begin{array}{c}
\frac{O G}{d} \sum_{i=1}^{3} Q 6_{2, i} x_{2}{ }^{3-i} \\
+\sum_{i=1}^{2} Q 6_{2, i+3} x_{2}{ }^{2-i}
\end{array}\right) \\
B_{E 2}=\left(0.25 x_{4}+0.95\right) \cdot x_{4}+\sum_{i=1}^{5} Q 6_{2, i} x_{2}{ }^{5-i} \\
B_{E 3}=\left(46.5-15 x_{1}\right) \cdot x_{2}+11.2 x_{1}-28.6
\end{gathered}
$$

where $x_{1}=B / d, x_{2}=C_{b}$ and $x_{3}=C_{m}$

Third damping component is the bilge keel damping coefficient $B_{B K}$ in Equation (27).

$$
\hat{B}_{B K}=A_{B K} \cdot \hat{\omega} \cdot \exp \left(B_{B K 1}+B_{B K 2} \cdot x^{B_{B K 3}}\right)
$$

The coefficients in Equation (27) are as shown in Equations (28)-(34).

$$
\begin{gathered}
A_{B K}=f_{1} \cdot f_{2} \cdot f_{3} \\
f_{1}=\left(x_{1}-2.83\right)^{2} \sum_{i=1}^{3} Q 7_{1, i} x_{2}{ }^{3-i}+\sum_{i=1}^{3} Q 7_{2, i} x_{2}{ }^{3-i} \\
f_{2}=\sum_{i=1}^{3} Q 7_{3, i} x_{6}{ }^{3-i} \\
f_{3}=\sum_{i=1}^{2} \sum_{j=1}^{3} Q 7_{3+i, j} x_{7}{ }^{3-j} x_{8}{ }^{3-i} \\
B_{B K 1}=x_{4}\left(5 x_{7}+0.3 x_{1}-0.2 x_{8}+\sum_{j=1}^{3} Q 7_{6, i} x_{6}{ }^{3-i}\right) \\
B_{B K 2}=-15 x_{7}+1.2 x_{2}-0.1 x_{1}+\sum_{j=1}^{3} Q 7_{7, i}\left(\frac{O G}{d}\right)^{3-i} \\
B_{B K 3}=2.5 \frac{O G}{d}+15.75
\end{gathered}
$$

where $x_{6}=\varphi_{a}(\mathrm{deg}), x_{7}=b_{B K} / B$ and $x_{8}=l_{B K} / L$.

Fourth damping component is the lift damping coefficient $B_{L}$ in Equation (35).

$$
\hat{B}_{L}=\frac{S_{L} U K_{n} l_{0} l_{R}}{2 \nabla B^{2}}\left(1-1.4 \frac{O G}{l_{R}}+0.7 \frac{O G^{2}}{l_{0} l_{R}}\right) \sqrt{\frac{B}{2 g}}
$$

where

$$
\begin{aligned}
& K_{n}=\frac{2 \pi d}{L}+\kappa\left(4.1 \frac{B}{L}-0.045\right) \\
& \kappa=\left\{\begin{array}{cc}
0 & C_{m} \leq 0.92 \\
0.1 & 0.92<C_{m} \leq 0.97 \\
0.3 & C_{m}>0.97
\end{array}\right. \\
& S_{L}=L d, l_{0}=0.3 d, l_{R}=0.5 d \text { and } U=F_{n} \sqrt{L g}
\end{aligned}
$$

Fifth damping component is the wave damping coefficient $B_{W}$ in Equation (36).

$$
\hat{B}_{W}=\frac{A_{1}}{\hat{\omega}} \cdot \exp \left(-0.6944 A_{2}\left(\log (\hat{\omega})-A_{3}\right)^{2}\right)
$$


The coefficients in Equation (36) are as shown in Equations (37)-(41).

$$
\begin{gathered}
A_{1}=A A_{1} \sum_{i=1}^{3} \sum_{j=1}^{4} \sum_{k=1}^{5} Q 1_{j+4 i, k} x_{1}{ }^{5-k} x_{2}{ }^{4-j} x_{4}{ }^{3-i} \\
A A_{1}=1.0+\left(1-x_{4}\right) \cdot \sum_{i=1}^{2} \sum_{j=1}^{4} \sum_{k=1}^{5} Q 1_{j+4 i, k} x_{1}{ }^{5-k} x_{2}{ }^{3-j} x_{3}{ }^{2-i} \\
A_{2}=\sum_{i=1}^{5} Q 2_{i} x_{4}{ }^{5-i} \\
A_{3}=A A_{3}+\sum_{i=1}^{7} \sum_{j=1}^{7} Q 3_{i, j} x_{2}{ }^{7-j} x_{4}{ }^{7-i} \\
A A_{3}=\sum_{i=1}^{4} Q 4_{1, i} x_{1}{ }^{4-i} \cdot \sum_{j=1}^{2} \sum_{k=1}^{4} Q 4_{2+j, k} x_{2}{ }^{3-k} x_{4}{ }^{2-j} \\
\cdot\left(\sum_{i=1}^{10} Q 5_{i}\left(x_{4}-\sum_{j=1}^{4} Q 4_{4, j} x_{1}{ }^{4-j}\right)^{10-i}+\sum_{i=1}^{3} Q 5_{i+9} x_{1}{ }^{3-i}\right)
\end{gathered}
$$

where $x_{4}=1-O G / d$.

Figure 5 shows the result for calculating the roll damping $B_{e}$. In Figure $5 \mathrm{a}$, the calculation results carried out in this study were verified by comparing them with the existing results [12] of the C11 container ship. The very well matched result for the $13 \mathrm{~K}$ oil chemical tanker, a vessel performed in this study, is shown in Figure 5b, which is calculated using the verified calculation code. Therefore, the Lv2 vulnerability of excessive acceleration mode was calculated by applying the roll damping coefficient value of the $13 \mathrm{~K}$ oil chemical tanker.

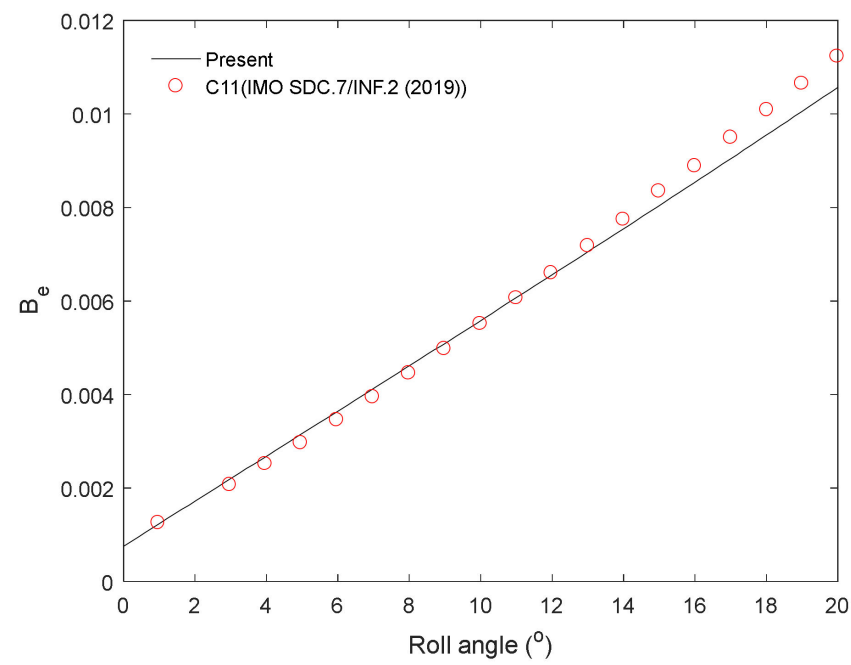

(a)

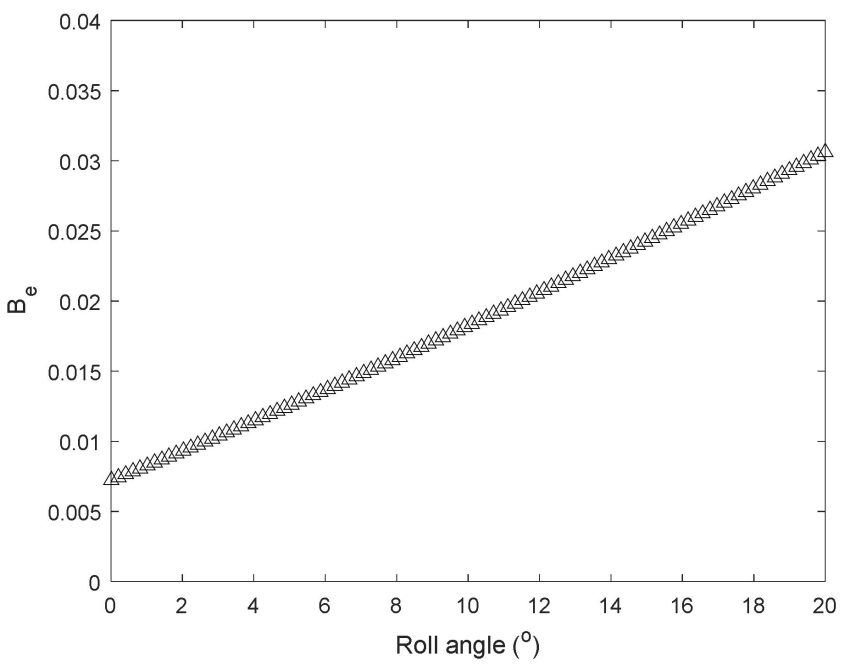

(b)

Figure 5. The roll damping coefficients depends on the roll angle estimated by Ikeda's method $\left(B_{e}=\hat{B}_{44}=\frac{B_{44}}{\rho \nabla B^{2}} \sqrt{\frac{B}{2 g}}\right)$. (a) C11 container ship (-: Present, $\bigcirc$ : [5]), (b) $13 \mathrm{~K}$ oil chemical tanker $(\Delta)$.

According to the Lv2 calculation procedure described so far, the results of vulnerability assessment under the same conditions are shown in Figure 6. Figure 6a is the result of calculating the Lv1 criterion evaluation according to the range of $h_{r}$, which is the height above the estimated roll axis of the position where sailor or passengers can be located, at $x / L=0.65$. Figure $6 \mathrm{~b}$ is the result of performing the Lv2 criterion under the same 
conditions. The Lv1 satisfaction criterion is $R_{E A 1}=4.64 \mathrm{~m} / \mathrm{s}_{2}$ and the Lv2 satisfaction criterion is $R_{E A 2}=0.00039$. In the Lv1 criterion, there are intervals that are not satisfied from $h_{r} \approx 50$, but the intact stability criterion has become less conservative through the result of allowing up to $h_{r} \approx 100$ in the Lv2 criterion. This means that the Lv1 criterion is more conservative than the Lv2 criterion, and thus the design margin of the stability criterion at Lv2 can be considered more. In addition, since the possibility of becoming vulnerable to excessive acceleration increases as the KG increases by the crew or cargo, an appropriate $K G$ value that satisfies the Lv2 criteria considering the loading conditions should be estimated. Through the evaluation accordingly, the basis for understanding the design characteristics of the ship's excessive acceleration mode can be presented.

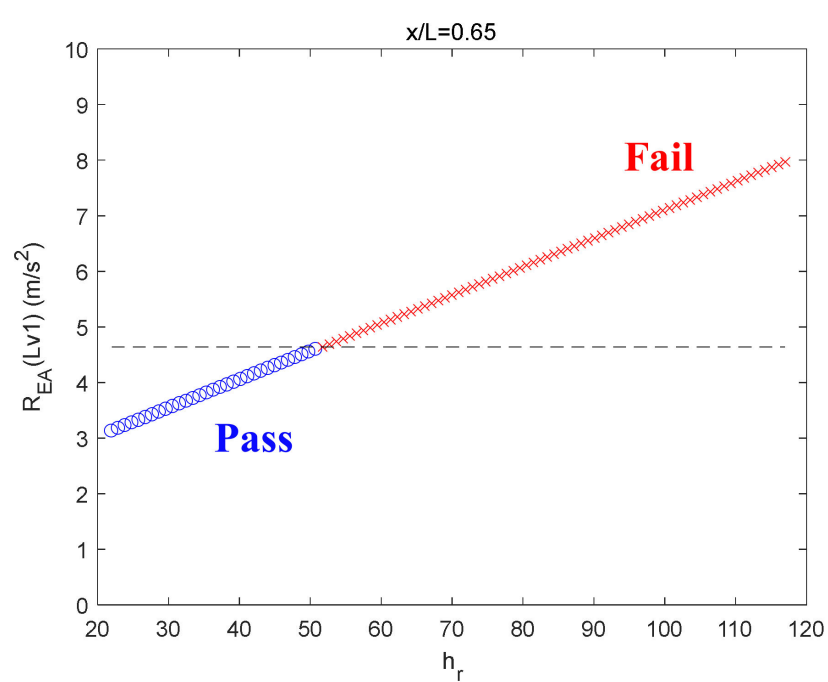

(a)

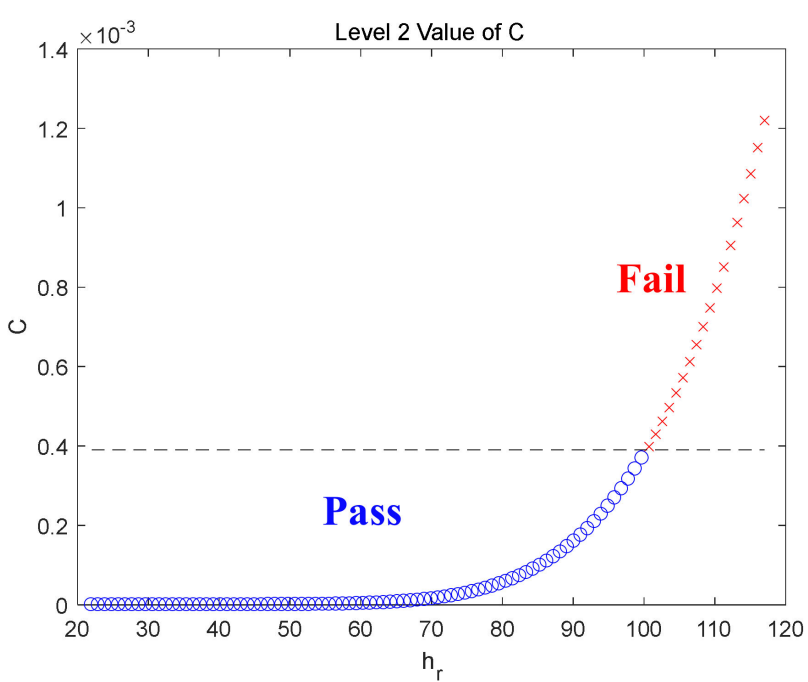

(b)

Figure 6. The vulnerability criteria assessment for excessive acceleration mode of the $13 \mathrm{~K}$ oil chemical tanker. (a) Lv1 criterion ( $\bigcirc$ : Pass, x: Fail), (b) Lv2 criterion ( $\bigcirc$ : Pass, x: Fail).

\section{Conclusions}

Recently, the IMO (International Maritime Organization) has reviewed technical issues considering the second generation intact stability criteria in the design stage of ships. Previous researchers have published a study on the application of second generation stability criteria to different types of ships $([16,17])$. In this paper, the evaluation procedure for Lv1 (Level 1) and Lv2 (Level 2) was introduced by paying attention to the excessive acceleration. We explained in detail the procedures of Lv1 (Level 1) and Lv2 (Level 2). When the Lv1 criteria considering simple hydrostatic calculations are not satisfied, the computational results of the Lv2 criteria based on mathematical modeling and the hydrodynamics are presented for a $13 \mathrm{~K}$ oil chemical tanker. The many calculations were carried out based on Lv2 according to $h_{r}$, which is the height above the estimated roll axis of the position where sailor or passengers can be located. The roll damping $B_{e}$ is the most important factor in the calculation of excessive acceleration mode Lv2 judgment and is carried out using the Ikeda's method. In this study, the roll damping value of the C11 container ship was calculated to verify the calculation code used to calculate the roll damping value compared with the existing results. We showed the calculation result of the roll damping value of the $13 \mathrm{~K}$ oil chemical tanker using the verified calculation code. The Lv1 criterion is more conservative than the Lv2 criterion, and thus the design margin of the stability criterion at Lv2 can be considered more. The higher the height of the center of gravity of the hull roll axis by crew or cargo overall, the more likely it is to be unstable to the excessive acceleration. The relatively low rolling periods of the ship and large changes in the hull shape in the vertical direction make the ships potentially vulnerable to excessive acceleration phenomena. Therefore, for the vessel vulnerable to excessive acceleration mode, even if 
they do not satisfy the most conservative Lv1 evaluation for various reasons, the minimum value of height $K G$ that satisfies the Lv2 stability criteria evaluation in consideration of loading conditions for sailing in the sea should be estimated and operated. We can maintain the profits of related domestic industries by developing the technical discussion on the second generation intact stability regulatory laws based on the computational results. The effects of these regulations on ships can be analyzed. Until now, there have been few papers showing many numerical intermediate results in the process of calculating Lv1 and Lv2 for the excessive acceleration in great detail. Therefore, it is expected to be able to prepare a response strategy early in ship design. In addition, we will carry out in-depth analysis by the calculations for verification through data of much more previous ships, direct stability assessment, and model tests in the future.

Author Contributions: Conceptualization, D.-M.S. and B.-Y.M.; Methodology, D.-M.S.; Software, D.-M.S.; Validation, D.-M.S.; Formal analysis, D.-M.S.; Investigation, D.-M.S. and B.-Y.M.; Resources, D.-M.S. and B.-Y.M.; Data curation, D.-M.S.; Writing—original draft preparation, D.-M.S.; Writingreview and editing, D.-M.S.; Visualization, D.-M.S.; Supervision, D.-M.S. and B.-Y.M.; Project administration, B.-Y.M.; Funding acquisition, D.-M.S. and B.-Y.M. All authors have read and agreed to the published version of the manuscript.

Funding: This research was funded by Development of Verification Technology of the IMO 2nd Generation Stability Criteria for Improving Ship Safety of the Ministry of Oceans and Fisheries, Korea (20180318).

Acknowledgments: This research was a part of the project titled Development of Verification Technology of the IMO 2nd Generation Stability Criteria for Improving Ship Safety.

Conflicts of Interest: The authors declare no conflict of interest.

\section{References}

1. IMO SDC 4/WP.4 Annex 1; Draft Guidelines of Direct Stability Assessment Procedures for Use with the Second Generation Intact Stability Criteria. International Maritime Organization: London, UK, 2017.

2. IMO SDC 5/INF 4 Add.1; Draft Guidelines of Direct Stability Assessment Procedures for Use with the Second Generation Intact Stability Criteria. International Maritime Organization: London, UK, 2017.

3. Belenky, V.; Bassler, C.C.; Spyrou, K.J. Development of Second Generation Intact Stability Criteria; Hydromechanics Department Report, Naval Surface Warfare Center Carderock Division-50-TR-2011/065; Naval Surface Warfare Center: West Bethesda, MD, USA, 2011.

4. Spyrou, K.J. The Nonlinear Dynamics of Ships in Broaching. Marie Curie Fellowsh. Ann. 2001, 1, 1-13.

5. IMO SDC 7/INF.2; Draft Guidelines of Direct Stability Assessment Procedures for Use with the Second Generation Intact Stability Criteria. International Maritime Organization: London, UK, 2019.

6. IMO SDC 2/WP.4; Draft Guidelines of Direct Stability Assessment Procedures for Use with the Second Generation Intact Stability Criteria. International Maritime Organization: London, UK, 2015.

7. IMO SDC 3/6/6; Draft Guidelines of Direct Stability Assessment Procedures for Use with the Second Generation Intact Stability Criteria. International Maritime Organization: London, UK, 2015.

8. IMO SDC 3/INF.10; Draft Guidelines of Direct Stability Assessment Procedures for Use with the Second Generation Intact Stability Criteria. International Maritime Organization: London, UK, 2015.

9. IMO SDC 3/WP.5; Draft Guidelines of Direct Stability Assessment Procedures for Use with the Second Generation Intact Stability Criteria. International Maritime Organization: London, UK, 2016.

10. IMO SDC 4/5/4; Draft Guidelines of Direct Stability Assessment Procedures for Use with the Second Generation Intact Stability Criteria. International Maritime Organization: London, UK, 2016.

11. IMO SDC 6/WP.6; Draft Guidelines of Direct Stability Assessment Procedures for Use with the Second Generation Intact Stability Criteria. International Maritime Organization: London, UK, 2019.

12. IMO SDC 7/WP.6; Draft Guidelines of Direct Stability Assessment Procedures for Use with the Second Generation Intact Stability Criteria. International Maritime Organization: London, UK, 2020.

13. Zheng, Y.H.; You, Y.G.; Shen, Y.M. On the radiation and diffraction of water waves by a rectangular buoy. Ocean Eng. 2004, 31, 1063-1082. [CrossRef]

14. Lee, C.; Kang, C. Hull Form Study for 21C 13 K Chemical Tanker; KRISO Model Test Report. No. BSIO2610-04601E; KRISO: Daejeon, Korea, 2004.

15. Kawahara, Y.; Maekawa, K.; Ikeda, Y. A simple prediction formula of roll damping of conventional cargo ships on the basis of Ikeda's method and its limitation. J. Shipp. Ocean. Eng. 2012, 2, 201. 
16. Shin, D.M.; Moon, B.Y.; Chung, J. Application of surf-riding and broaching mode based on IMO second-generation intact stability criteria for previous ships. Int. J. Nav. Archit. Ocean. Eng. 2021, 13, 545-553. [CrossRef]

17. Shin, D.M.; Chung, J. Application of dead ship condition based on IMO second-generation intact stability criteria for $13 \mathrm{~K}$ oil chemical tanker. Ocean Eng. 2021, 238, 109776. [CrossRef] 